Print ISSN: 2233-4165 / Online ISSN 2233-5382

doi:http://dx.doi.org/10.13106/jidb.2020.vol11.no4.19

\title{
The Effect of Hierarchy Culture on Clan Leadership and Organizational Commitment of Export-Driven SMEs
}

\author{
Hyuk Young KIM*
}

Received: February 26, 2020 Revised: March 152020 Accepted: April 05, 2020.

\begin{abstract}
Purpose: The purpose of this study examines the mediating effect of clan leadership in the relationship between hierarchy culture and organizational commitment. Most previous research focused on the relationship between organizational culture and organizational performance or organizational culture and job satisfaction. There are few empirical studies that focus on organizational commitment data because it is difficult to collect in many cases of export-driven small and medium sized enterprises. However, this research measures affective commitment, continuance commitment, and normative commitment differently than previous research, which is mostly focused on the hierarchy culture, clan leadership, and organizational commitment measurements. Research design, data, methodology: Conceptual research model is based on the studies of Cameron and Quinn (2011), and Gungor and Sahin (2018). The model is designed with three constructs such as hierarchy culture, organizational commitment, and clan leadership. The monitor culture and coordinator culture are as proxy for the hierarchy culture. The affective commitment, continuance commitment, and normative commitment are as proxy for the organizational commitment. And also the facilitator leadership and mentor leadership are as proxy for the clan leadership. Based on three hundred cases such as export-driven small and medium sized enterprises (SMEs), this study verify the hypothesis. Hypothesis was analyzed with the structural equation modeling. Results: In case of export-driven small and medium sized enterprises (SMEs), clan leadership acts as a mediator in the relationship between hierarchy culture and organizational commitment. In case of export-driven small and medium sized enterprises (SMEs) with high organizational commitment, clan leadership acts as a mediator in the relationship between hierarchy culture and organizational commitment. In case of export-driven small and medium sized enterprises (SMEs) with low organizational commitment, clan leadership did not act as a mediator in the relationship between hierarchy culture and organizational commitment. Conclusions: By controlling for the mediating effect of clan culture, this study have improved the academic contributions as well as policy and practical implications through empirical study of clan leadership that affect organizational commitment in the fields of hierarchy culture. In addition, this study means that the mediating effects on the variables of clan leadership were examined.
\end{abstract}

Keywords : Hierarchy Culture, Clan leadership, Organizational Commitment, Export-Driven Small and Medium Sized Enterprises (SMEs), Structured Equation Modeling (SEM)

JEL Classification Code : F11, F15, Q22, R26

\section{1. 서론}

수출주도형 중소기업은 한국형 히든챔피언 육성, 글로벌 강소기업 육성, 월드클래스 300 육성, 월드 챔프 육성, 수출 강소기업 육성, 코스닥형 히든 챔피언 육성, 수출 강소기업 Plus 500 등과 같이

*Instructor, Department of Policy Administration, Jungwon University, Chungcheongbuk-do, South Korea,

Email: kimlucy34@gmail.com

() Copyright: Korean Distribution Science Association (KODISA)

This is an Open Access article distributed under the terms of the Creative Commons Attribution NonCommercial License (https://creativecommons.org/licenses/by-nc/4.0/) which permits unrestricted non-
정부기관과 연구자들에 따라 다양한 명칭으로 부르고 있다. 수출 주도형 중소기업에 대한 정의와 개념이 아직까지 명확하게 정립되고 있지 않은 상황이나, 본 연구에서는 수출주도형 중소기업을 수출 1 억불 이상이고 지속적으로 글로벌 시장에서 시장지배력을 유지하고 있는 우리나라의 강소 중소기업으로 정의한다The Export-Import Bank of Korea, 2010). 이 수출주도형 중소기업은 독일 히든 챔피언의 개념을 우리나라에 도입해서 한국형 히든 챔피언 육성을 목표로 하고 있는 수출주도형 중소기업을 말한다.

히든챔피언은 독일의 수출주도형 중소기업을 말하는데, 이 기업은 수출주도형 중소기업으로 해당 분야 세계시장 점유율 1 3 위를 
유지하는 중소기업으로 연매출 30 억 유로를 달성하는 기업을 말한다. 독일은 전 세계 히든챔피언의 $50 \%$ 를 차지하고 있으며, 인구 100 만명 당 히든챔피언 수가 14 명이나 되는 히든챔피언 강국이다. 오늘날 독일이 히든챔피언 강국이 된 것은 역사적인 소국 분립주의가 낳은 국제화 역량, 전통적인 기술역량, 독일 시장 내에서의 치열한 경쟁을 통한 경쟁력, 산업 클러스터와 기업가 클러스터의 독려, 낮은 노동비용과 뛰어난 직업 교육, 전략 지정학적 중심지의 경제사회적 요인이 독일을 강소기업 국가로 만든 원천이 되고 있다.

본 연구에서는 수출 주도형 중소기업을 대상으로 Cameron and Quinn(2011)의 연구에 기초해서 수출 주도형 중소기업의 조직문화와 조직몰입 간의 관계에서 집단형 리더십의 역할에 대해서 탐색하고자 한다. Cameron and Quinn(2011)은 경쟁가치모형(CVF)에 따른 조직문화 유형을 위계형, 집단형, 개발형, 합리형 조직문화의 4 가지 조직문화 유형을 제시하였다. 이들은 경쟁가치모형(CV)을 기반으로 한 조직문화 유형을 조직문화의 안정성 및 통제, 유연성 및 신중, 내부집중 및 통합화, 외부집중 및 차별화의 이분법적 기준으로 4 가지 조직문화 유형을 분류하였다. 이들은 위계형 조직문화와 집단형 리더십이 내부집중 및 통합화의 관점에서 조직문화의 유사점을 보이는 반면에, 위계형 조직문화와 집단형 리더십이 조직문화의 안정성 및 통제, 유연성 및 신중의 관점에서 조직문화의 차이점을 보였다.

본 연구의 필요성은 글로벌 시장에 진출하고 있는 우리나라 수출기업의 지속적인 성장가능성을 높이기 위해서 해외시장의 수출경쟁력과, 수출상품의 가격경쟁력을 높이는 것이 중요하다. 이 수출기업의 대외경쟁력을 높여서 해외에 우수한 수출기업과 경쟁하기 위해서 무엇보다 중요한 것은 좋은 조직문화가 구축되어 있어야 하고, 강력한 중간관리자의 리더십이 발휘되어서 조직구성원의 조직몰입이 강화되어야 수출성과가 증가하는데, 이에 대한 심층적인 연구가 미흡한 상태이다. 특히 수출기업 중에서 글로벌 시장의 히든 챔피언과 경쟁하고 있는 우리나라의 수출주도형 중소기업을 대상으로 중소기업의 조직문화와 조직몰입도 간의 관계에서 수출주도형 중소기업의 중간관리자의 집단형 리더십에 대한 연구가 미흡한 상태이다. 본 연구는 우리나라의 중소기업 중에서 수출주도형 중소기업을 대상으로 정책적 측면에서 산학연계직업훈련체계, 산업클러스터와 지역혁신체계에 대한 시사점을 제시하고, 실무적 측면에서 기업 사회적책임과 기업가정신에 대한 시사점을 제시하고자 한다.

본 연구의 목적은 수출주도형 중소기업을 대상으로 중소기업의 집단형 리더십에 따른 위계형 조직문화가 조직몰입에 미치는 영향을 분석하고자 하는 것이다. 본 연구에서 수출주도형 중소기업의 리더십에 따른 조직문화와 조직몰입 간의 관련성을 분석하고자 하는 것은 오늘날 OECD 국가들이 연평균 $19 \%$ 의 경제성장률을 보이고 있는데 비해서, 독일의 히든챔피언과 핀란드의 강소기업은 연평균 $3.0 \%$ 이상의
경제성장률을 달성하고 있다는 점이다. 이 기업들은 글로벌 시장에서 다른 기업들과 차별화된 조직문화를 구축하고 있고, 중간관리자의 강력한 리더십을 통해서 조직몰입을 강화시키면서 수출성과를 높이고 있다는 점을 본 연구를 통해서 탐색하고자 하는 것이다.

이 연구목적을 달성하기 위하여 본 연구는 다음과 같은 연구 과제를 설정하였다. 첫째는 중소기업의 조직문화가 집단형 리더십에 미치는 영향을 탐색하고자 한다. 수출주도형 중소기업 중에서 집단형 리더십을 발휘하는 중소기업과 위계형 문화 간의 상관관계를 분석하고자 한다. 둘째는 중소기업의 집단형 리더십이 조직몰입에 미치는 영향을 탐색하고자 한다. 수출주도형 중소기업의 리더십 중에서 조직 내에 촉진자와 선도자의 역할을 하는 집단형 리더십이 조직몰입에 미치는 영향을 분석하고자 한다. 셋째는 중소기업의 조직문화가 조직몰입에 미치는 영향을 분석하고자 한다. 수출주도형 중소기업의 조직문화가 조직구성원의 정서적 몰입을 높여 주는지, 아니면 지속적 몰입과 규범적 몰입을 강화시켜 주는지를 비교 분석하고자 한다.

\section{2. 이론적 배경}

\section{1. 위계형 조직문화와 집단형 리더십 간의 관계}

조직문화 유형 중에서 위계형 조직문화는 집단형 리더십과 밀접한 상관관계가 있다. 위계형 조직문화와 집단형 리더십은 조직문화의 특성이 외부집중 및 차별화(extemal focus and differentiation)의 관점이 아닌, 내부집중 및 통합화(intemal focus and integration)의 관점에서 유사한 특성을 보인다. 또한 위계형 조직문화가 조직문화의 안정성 및 통제(stability and contro)에 주안점이 있는 반면에, 집단형 리더십은 조직문화의 유연성 및 신중(flexibility and discretion)에 주안점을 두고 있다는 점에서 차이가 있다(Cameron \& Quinn, 2011; Igo \& Skitmor, 2000).

Igo and Skitmor(2006)는 Cameron and Quinn(2011)의 경쟁가치모형(CVF)에 따른 위계형, 집단형, 개발형, 합리형 조직문화의 4 가지 조직문화 유형을 분류하는 세부적인 기준을 제시하였다. Cameron and Quinn(2011)의 연구에 따르면 위계형 조직문화와 집단형 리더십이 내부유지에 집중하면서 안정성 및 통제, 유연성 및 신중을 강화해야 한다는 점을 강조하였다. Igo and Skitmor(2006)는 위계형 조직문화를 구축하기 위한 조직문화의 전반적인 분위기가 명료한 직무설정, 엄격한 규칙시행의 필요성을 강조한 반면에, 집단형 리더십을 구축하기 위해서 조직문화의 유연성을 높이고 신중하게 대응해 나가려면 사람들에게 집중하고 고객에 대한 민감성을 높일 필요가 있다는 점을 강조하였다. 
거대한 조직들과 공공기관들은 일반적으로 계층제에 지대한 영향을 받고 있으며, 위계형 조직문화에서 궁극적으로 조직의 장기적인 관심은 조직의 안정성, 예측 가능성, 그리고 효과성이라고 거듭 강조했다(Alkindi \& Chaldler, 2018). 집단형 리더십은 특히 서로 어우러지는 가치와 목표, 화합, 참여, 그리고 개개인의 특성, 개성을 강조한다. 집단형 리더십의 전형적인 특색은 조직구성원들 서로간의 화합된 단결성과 조직구성원들 간의 서로 어우러지는 결합이다Nanjundeswaraswamy \& Swamt, 2014). Szzepanska-Woszcyna(2015)는 혁신적 조직문화에서 최고경영자의 리더십이 조직구성원의 행태에 유의한 정(+)의 영향을 미친다고 하였는데, 특히 최고경영자가 규범적인 리더십을 발휘할 때 조직을 혁신적으로 변화시켜서 조직성과에 긍정적인 영향을 미쳤다는 점을 제시하였다. Nazanan et al.(2017)는 국가문화와 조직성과 간의 관계에서 조직문화가 유의한 정(+)을 미친다고 하였다. 이들은 권력집중, 개인주의, 불확실성 회피, 남성성의 국가문화가 리더십과 조직문화에 직접적인 영향을 미쳐서 조직성과 에 유의한 영향을 미쳤다는 점을 강조하였다(Guiso, Sapienza, \& Zingales, 2015).

제조업에서 리더십과 조직성과 간의 관계에서 리더십의 영향은 제조업뿐만 아니라, 서비스업에서도 유사한 성과가 나타나는데, 유선전자 상거래 시장에서 지식경영과 혁신적 조직 문화가 구축된 조직에서 조직성과가 증가하였다(Lestani, Muhdaliha, \& Putra, 2020). 특히 혁신적인 조직문화를 가지고 있는 조직에서 이슬람 리더십은 조직구성원의 태도와 참여도를 높이는데 효과적으로 작용하였다(Meiyani \& Putra, 2019; Razak, Gunawan, Fitriany, Hidayat, \& Aditya, 2019). 이는 이슬람 조직문화는 권력집중과 남성성이 강한 조직문화의 특성을 보이고 있으며, 이슬람 조직문화에서 중간관리자는 다른 서구의 리더들과 다르게 카리스마 리더십을 발휘함으로써 조직성과를 높였다.

Acer(2012)는 조직문화 유형 중에서 위계형 조직문화는 집단형 리더십과 밀접한 상관관계가 있다는 점을 강조하였다. 조직문화의 특성이 외부집중 및 차별화(extemal focus and differentiation)의 관점이 아닌, 내부집중 및 통합화(intemal focus and integration)의 관점에서 위계형 조직문화와 집단형 리더십 간의 유사한 특성을 보인다. 또한 위계형 문화가 조직문화의 안정성 및 통제(stability and control)에 주안점이 있는 반면에, 집단형 리더십은 조직문화의 유연성 및 신중(flexibility and discretion)에 주안점을 두고 있다는 점에서 차이가 있다.

\section{2. 위계형 조직문화와 집단형 리더십, 조직몰입 간의 관계}

조직문화 유형 중에서 위계형 조직문화의 특성이 높은 조직들은 다른 조직들에 비해서 집단형 리더십과 유사한 조직문화의 특성을 보인다. 위계형 조직문화는 조직이 형식과 구조를 중시하고 내부통제를
강조하기 때문에 규칙과 방침에 의한 조직효율성을 중시하면서, 체계적인 조직관리가 이루어지고 정보관리와 문서화가 잘되고 있다는 장점을 가지고 있다(Alsoulami, Banjar, \& Mohran, 2018). 또한 위계형 조직문화가 조직 내에 경직된 규정과 절차 준수로 인해 외부환경에 적절하게 대응하지 못하게 되면 형식주의와 관료주의의 부작용을 보이게 된다. 이 위계형 조직문화는 조직 내부활동에 집중하고 통합화를 통한 조직 효율성을 높이고 있다는 점에서 집단형 리더십과 유사점을 보이고 있다(Nazarian, Atkinson \& Foroudi, 2017).

Mastroianni (2014)의 연구에 따르면 위계형 조직문화와 집단형 리더십이 내부 조직활동에 집중하고 통합화를 지향한다고 하는 점에서 유사한 조직문화의 특성을 보이고 있으며, 이 위계형 조직문화는 조직 내에 리더를 촉진하고 선도하는 집단형 리더십에 직접적인 영향을 미친다. 집단형 리더십은 촉진자 리더십과 선도자 리더십의 형태로 나타나는데, 촉진자 리더십은 관리자와 추종자들 간의 관계가 서로 응집력과 도덕성에 중점을 두고, 항상 추종자들 개개인의 생각과 개성을 권장하려고 노력하는데 있으며, 선도자 리더십은 팀워크, 개방성, 그리고 강한 의사소통 능력을 통해서 관리자는 추종자들을 도와줄 수 있고, 추종자들의 일 뿐만 아니라 개개인의 사적인 일까지도 걱정해주고 위로해 주는 역할을 한다.

조직몰입은 개인이 장기간 조직에 소속되는 과정에서 개인과 조직 간의 관계가 심리적으로 일치하거나, 행태적으로 동화되는 현상을 말한다. 심리적 일치 현상은 조직에 대해서 조직구성원이 인식하고 있는 정서적, 지속적, 혹은 규범적 몰입과 같은 심리적으로 인식하는 정도를 말하며, 행태적 동화는 개인이 조직에 대해 인식하고 있는 태도, 혹은 행동에 대한 몰입 정도를 말한다(Shin \& Lee, 2013; Kang, 2014; Mdaren, Head, Yuan, \& Chan, 2011). 본 연구는 조직구성원들이 조직에 대해서 인식하는 심리적 일치 현상을 중심으로 조직몰입을 논의하고자 한다. 정서적 몰입은 조직구성원과 조직 간의 관계가 감정적 애착에 관심을 두고 있는 반면에, 지속적 몰입은 거래적 몰입 행태를, 규범적 몰입은 도덕적 의무감에 초점을 맞추고 있다는 점에서 차이가 있다(AlJabari \& Ghazzawi, 2019; Meyer \& Allen, 1997).

조직 내에 중간관리자의 리더십은 조직몰입을 강화하는데 효과적으로 작용하였다. Doan et al. (2020)은 중간관리자의 변혁적 리더십이 거래적 리더십보다 조직몰입에 유의한 정(+)의 영향을 미쳤다는 점을 제시하였다. 이들은 중간관리자가 가지고 있는 감성적 지능과 사업성과 간의 상관관계 있다는 것을 강조하였다. Lee(2018)의 연구는 Doan et al. (2020)와 유사하게 유통조직에 있어서 직업특성과 팀 창의성 간의 관계에서 중간관리자의 변혁적 리더십이 매개효과로 작용하였다는 것을 제시하였다. 이 중간관리자의 리더십 유형은 민간조직뿐만 아니라, 공조직의 조직몰입에 긍정적인 영향을 미쳤다는 연구결과를 지지하는 연구이다(Suong, Thanh, \& Dao, 2019). 
리더십 유형과 조직성과 간의 관계에서 중간관리자의 신뢰성과 효능감이 매개효과로 작용하였다. Yang and Ju(2011)는 중간관리자의 지시적, 지원적, 참여적, 성취적 리더십의 유형에 따라 조직성과에 차이를 보였다. 이들은 중간관리자의 리더십이 조직구성원에게 효과적으로 작용하기 위해서 무엇보다 조직구성원에 대한 신뢰성과 효능감이 높은 중간관리자가 다른 리더들보다 조직성과에 긍정적인 영향을 미쳤다(Mushtaq, Amjad, \& Saeed, 2014). Ghassemzadeh et al.(2013)는 지식경영이 구축되어 있는 조직에서 조직문화와 조직몰입은 전략적 지식보다 전술적 지식을 공유하는데 더 효과적으로 작용하였다는 점을 강조하였다. 이들은 조직문화 중에서 팀 지향적 조직문화가 지원적 조직문화보다 더 높은 조직성과의 차이를 보였다.

위계형 조직문화와 조직몰입 간의 관련성에 대한 연구를 보면, Arank et al.2019)는 요르단에 있는 $\Pi$ 중소기업은 위계형 조직문화의 유형이 많으며, 이 위계형 조직문화가 조직구성원으로 하여금 조직몰입을 강화하고 사업성과를 높이는데 긍정적으로 작용하였다는 점을 제시하였다. 특히, 요르단 $\Pi$ 산업에 참여하고 있는 중소기업은 위계형 조직문화 중에서 조정자 문화가 감시자 문화가 더 많은 비중을 차지하고 있으며, 이 위계형 조직문화와 조직몰입 간의 정 $(+)$ 의 상관관계가 있다는 점을 강조하였다. 또한 Arditi et al.(2017)는 건설산업에 참여하고 중소기업의 리더가 집단형 리더십을 발휘함으로써 조직몰입을 높이고 있다는 점을 제시하였다. 이들은 건설산업의 중소기업은 조직 내에 집단형 리더십을 통해서 건설분야의 공사지연 혹은 공사중단과 같이 조직몰입을 약화시키는 요인들을 줄이는 집중하였다.

\section{3. 연구조사방법}

\section{1. 연구모형 및 가설 설정}

본 연구는 수출주도형 중소기업의 조직문화가 집단형 리더십과 조직몰입에 미치는 영향에 관한 선행연구에 기초해서 개념적 연구모형을 설정하였다. 본 연구의 개념적 연구모형에 포함된 변수들을 살펴보면, 먼저 조직문화 요인은 위계형 조직문화를 중심으로 조정자 문화, 감시자 문화의 2 가지 변수가 연구모형에 포함되었으며(Gulosino, Franceschini, \& Hardman, 2016; Gungor \& Sahin, 2018), 집단형 리더십 요인은 촉진자 리더십, 선도자 리더십의 2 가지 하위변수가 연구모형에 포함되었대(Cameron \& Quinn, 2011; Felipe, Roldan, \& Leal-Rodniguez, 2017). 또한 조직몰입 요인은 정서적 몰입, 지속적 몰입, 규범적 몰입의 3 가지 하위변수가 연구모형에 포함되었다Meyer \& Allen, 1997; Al-Jabari \& Ghazzawi, 2019).
본 연구는 수출주도형 중소기업의 조직문화, 집단형 리더십, 조직몰입 간의 관련성에 대한 선행연구에 기초하여 다음과 같은 연구가설을 설정하였다.

H1: 수출주도형 중소기업의 조직문화가 집단형 리더십에 유의한 정(+)의 영향을 미칠 것이다.

H2: 수출주도형 중소기업의 집단형 리더십이 조직몰입에 유의한 정(+)의 영향을 미칠 것이다.

H3: 수출주도형 중소기업의 조직문화가 조직몰입에 유의한 정(())의 영향을 미칠 것이다.

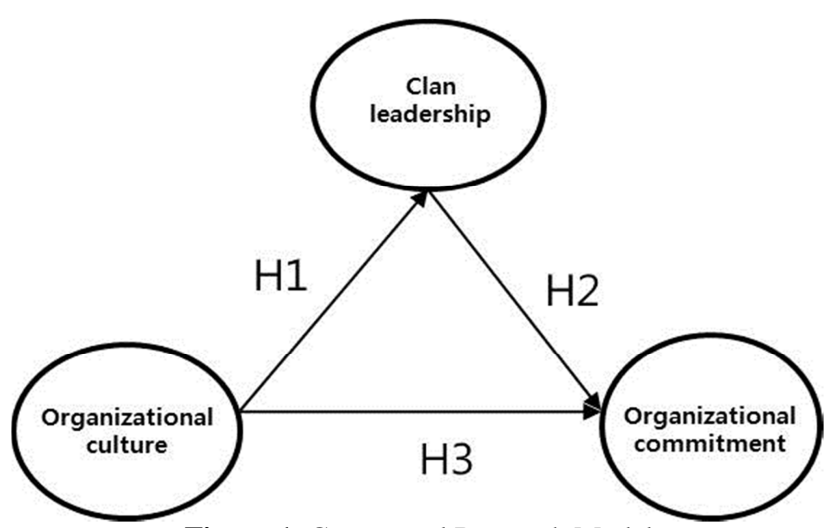

Figure 1: Conceptual Research Model

\section{2. 통계분석방법}

본 연구의 자료분석은 세 단계로 수행되었다. 첫 번째 단계는 조사대상자의 인구통계학적 특성, 조직문화, 집단형 리더십, 조직몰입에 포함된 기초통계량의 분포를 분석하기 위하여 빈도분석(frequency analysis)과 기술통계분석(descriptive statistic analysis)을 수행하였다. 두 번째 단계는 조직문화, 집단형 리더십, 조직몰입에 포함된 측정항목의 신뢰성과 타당성을 검증하기 위하여 신뢰성분석(reliability analysis)과 타당성분석(factor analysis)을 수행하였다. 본 연구의 신뢰성 분석은 신뢰도계수(cronbach's alpha)에 기초하여 측정하였다. 타당성 분석은 탐색적 요인분석(explored factor analysis)과 확인적 요인분석(confimatory factor analysis)을 수행하였다. 세 번째 단계는 본 연구에서 제시한 조직문화, 집단형 리더십, 조직몰입 간의 상호작용효과를 검증하는 단계로 구조방정식 모형(structure equation mode))을 수행하였다. 본 연구에서는 조직문화, 집단형 리더십, 조직몰입 간의 상호작용효과를 구체적으로 검증하기 위하여 조직몰입 전체집단, 조직몰입 고집단, 조직몰입 저집단의 3 개의 연구모형을 제시하여 실증분석을 수행하였다. 본 연구의 연구모형 및 연구가설의 검증은 유의수준은 $95 \%$ 에서 연구가설을 채택하고 기각하였으며, AMOS 20.0 과 SPSS 20.0 통계패키지를 활용하여 실증분석을 수행하였다. 


\section{4. 실증연구분석}

\section{1. 인구통계학적 특성}

본 연구는 수출주도형 중소기업을 대상으로 2019 년 8 월 21 일부터 9 월 30 일까지 40 일간 조사하였으며, 전체 800 부의 설문지를 배포하여 $39.6 \%$ 의 수거율에 해당하는 317 부의 설문지를 입수하였다. 이 중에서 오류와 오기가 있는 설문지 17 부를 제외하고 최종적으로 $37.5 \%$ 에 해당되는 300 부의 설문지를 최종분석에 사용하였다. 본 연구에서 설문조사에 대한 회수율이 낮은 것은 조사대상이 일반적인 중소기업을 대상으로 한 것이 아니고, 수출주도형 중소기업을 대상으로 조사했기 때문이며, 또한 조사대상표본을 추출하는데 있어서 조직에서 리더십을 발휘하고 조직문화를 잘 알고 있는 중간관리자를 대상으로 층화추출 하였기 때문이다.

본 연구의 인구통계학적특성 분석결과는 다음과 같다. 조사대상별 분포를 보면 전체 300 명의 설문 조사 대상자 중에서 남자가 220 명(73.4\%)으로 여자 80 명(26.6\%)보다 더 높은 분포를 보였다. 연령별 분포를 보면 40 세 이상이 187 명(624\%)으로 40 세 미만 113 명(37.6\%)보다 더 높은 분포를 보였으며, 학력별 분포를 보면 4 년제 대졸 이상이 225 명(75.0\%)으로 전문대 졸 이하 75 명(25.0\%)보다 더 높은 분포를 보였다. 또한 근속기간별 분포를 보면 10 20 년 미만이 119 명(39.7\%)로 가장 높은 분포를 보였고, 그 다음으로 10 년 미만이 110 명(36.5\%), 20 년 이상 71 명(23.8\%) 순으로 분포의 차이를 보였다.
조사대상자의 분포를 요약하면 40 세 이상(62.4\%)이면서 4 년제 대졸 이상(75.0\%)의 학력을 갖추고 있고, 근속경력은 대략 10 20 년 미만(39.7\%)의 경력을 가진 수출주도형 중소기업의 중간관리자급 이상이 조사에 포함되었다.

\section{2. 신뢰성 및 타당성 검증 결과}

\subsection{1 탐색적 요인분석 결과}

\subsubsection{1 조직문화}

조직문화, 집단형 리더십, 조직몰입에 대한 탐색적 요인분석결과는 다음과 같다. 첫째, 조직문화 요인에 포함된 전체 8 개의 문항에 대해서 요인분석을 수행하여 다음과 같은 분석결과를 얻었다. 분석결과를 보면 조직문화 요인은 조정자 문화 4 문항, 감시자 문화 4 문항으로 각각 측정되었다. 조직문화 요인의 하위변인에 대한 고유값(eigenvalue)을 보면, 감시자 문화 3.94, 조정자 문화 3.69 로 고유값의 차이를 보이고 있다. 다음으로 조직문화 요인의 하위변인에 대한 분산설명력(\% of variance)에 대한 결과를 보면, 감시자 문화가 $3632 \%$, 조정자 문화 $34.61 \%$ 로 분산설명력의 차이를 보이고 있으며, 조직문화 요인의 하위요인의 전체 분산설명력은 $70.93 \%$ 로 검증 되었다. 마지막으로 조직문화 요인의 신뢰성을 보면 감시자 문화가 0.91 , 조정자 문화 0.93 로 신뢰성의 차이를 보였다.

Table 1: Explored Factor Analysis Results for Organizational Culture

\begin{tabular}{|c|c|c|}
\hline Items & Monitor culture & Coordinator culture \\
\hline The organization is a very controlled and structured place. & $\underline{0.88}$ & 0.24 \\
\hline The glue that holds the organization together is running smooth. & $\underline{0.84}$ & 0.23 \\
\hline The management style is characterized by security of employment, conformity, predictability, stability. & $\underline{0.80}$ & 0.13 \\
\hline The glue that holds the organization together is formal rules and policies. & $\underline{0.77}$ & 0.19 \\
\hline The organization emphasizes permanence and stability. & 0.22 & $\underline{0.87}$ \\
\hline The organization defines success on the basis of efficiency. & 0.29 & $\underline{0.83}$ \\
\hline The organization emphasizes efficiency and control. & 0.29 & $\underline{0.80}$ \\
\hline The leadership is generally considered to exemplify coordinating, organizing, or smooth-running \\
efficiency. & 0.20 & $\underline{0.78}$ \\
\hline Eigenvalue & 3.94 & 3.69 \\
\hline \% of variance & 36.32 & 34.61 \\
\hline Cumulative \% & 36.32 & 70.93 \\
\hline Cronbach's alpha & 0.91 & 0.93 \\
\hline
\end{tabular}

\subsubsection{2 집단형 리더십}

집단형 리더십 요인에 포함된 전체 8개의 문항에 대해서 요인분석을 수행하여 다음과 같은 분석결과를 얻었다. 분석결과를 보면 집단형
리더십은 촉진자 리더십 4 문항, 선도자 리더십 4 문항으로 각각 측정되었다. 집단형 리더십요인의 하위변인에 대한 고유값(eigenvalue)을 보면, 촉진자 리더십 2.73 , 선도자 리더십 2.66 , 로 고유값의 차이를 
보이고 있다. 다음으로 집단형 리더십 요인의 하위변인에 대한 분산설명력(\% of variance)에 대한 결과를 보면, 촉진자 리더십이 $37.29 \%$, 선도자 리더십 $3224 \%$ 로 분산설명력의 차이를 보이고 있으며, 집단형
리더십 요인의 하위요인의 전체 분산설명력은 $69.53 \%$ 로 검증 되었다. 마지막으로 집단형 리더십 요인의 신뢰성을 보면 촉진자 리더십이 0.89 , 선도자 리더십 0.87 로 신뢰성의 차이를 보였다.

Table 2: Explored Factor Analysis Results for Clan Leadership

\begin{tabular}{|c|c|c|}
\hline Items & Facilitator leadership & Mentor leadership \\
\hline The organization is a very personal and faclitating. & $\underline{0.92}$ & 0.19 \\
\hline The glue that holds the organization together is loyalty and mutural trust. & $\underline{0.84}$ & 0.14 \\
\hline The management style is characterized by teamwork, consensus, and participation. & $\underline{0.83}$ & 0.16 \\
\hline The glue that holds the organization together is commitment runs high. & $\underline{0.76}$ & 0.20 \\
\hline The organization emphasizes human development. & 0.12 & $\underline{0.83}$ \\
\hline $\begin{array}{c}\text { The organization defines success on the basis of teamwork, employee commitment, and concern for } \\
\text { people. }\end{array}$ & 0.15 & $\underline{0.75}$ \\
\hline The organization emphasizes high trust and participation persist. & 0.14 & $\underline{0.73}$ \\
\hline The leadership is generally considered to exemplify mentoring, or nurturing & 0.15 & $\underline{0.66}$ \\
\hline Eigenvalue & 2.73 & 2.66 \\
\hline Cumulative \% & 37.29 & 32.24 \\
\hline Cronbach's alpha & 37.29 & 69.53 \\
\hline
\end{tabular}

\subsection{3. 조직몰입}

조직몰입 요인에 포함된 전체 15 개의 문항에 대해서 요인분석을 수행하여 다음과 같은 분석결과를 얻었다. 분석결과를 보면 조직몰입 요인은 정서적 몰입 5 문항, 지속적 몰입 5 문항, 규범적 몰입 5 문항으로 각각 측정되었다. 조직몰입 요인의 하위변인에 대한 고유값(eigenvalue)을 보면, 지속적 몰입 3.82, 정서적 몰입 3.42, 규범적 몰입 3.32 로 고유값의 차이를 보이고 있다. 다음으로 조직몰입 요인의
하위변인에 대한 분산설명력(\% of vaniance)에 대한 결과를 보면, 지속적 몰입이 $25.47 \%$, 정서적 몰입 $22.80 \%$, 규범적 몰입 $22.13 \%$ 로 분산설명력의 차이를 보이고 있으며, 조직몰입 요인의 하위요인의 전체 분산설명력은 $70.41 \%$ 로 검증 되었다. 마지막으로 조직몰입 요인의 신뢰성을 보면 정서적 몰입이 0.91 , 지속적 몰입 0.87 , 규범적 몰입 0.86 로 신뢰성의 차이를 보였다.

Table 3: Explored Factor Analysis Results for Organizational Commitment

\begin{tabular}{|c|c|c|c|}
\hline Items & Continuancecommitment & Affective commitment & Normative commitment \\
\hline It would be too costly for me to leave my organization now. & $\underline{0.83}$ & 0.02 & 0.04 \\
\hline $\begin{array}{l}\text { Too much in my life would be disrupted if I decided to leave } \\
\text { my organization now. }\end{array}$ & $\underline{0.82}$ & 0.09 & 0.10 \\
\hline $\begin{array}{l}\text { It would be very hard for me to leave my organization right } \\
\text { now, even if I wanted to. }\end{array}$ & $\underline{0.77}$ & 0.07 & 0.15 \\
\hline $\begin{array}{l}\text { I feel that I have very few options to consider leaving this } \\
\text { organization. }\end{array}$ & $\underline{0.76}$ & 0.15 & 0.05 \\
\hline $\begin{array}{l}\text { Right now staying with my organization is matter of necessity } \\
\text { as much desire. }\end{array}$ & $\underline{0.75}$ & 0.10 & 0.09 \\
\hline I really feel as if this organization's problems are my own. & 0.10 & $\underline{0.91}$ & 0.04 \\
\hline $\begin{array}{l}\text { I think that I could easily become as attached to another } \\
\text { organization as I am to this one. }\end{array}$ & 0.16 & $\underline{0.76}$ & 0.12 \\
\hline $\begin{array}{l}\text { I would be very happy to spend the rest of my career with this } \\
\text { organization. }\end{array}$ & 0.17 & $\underline{0.75}$ & 0.05 \\
\hline $\begin{array}{l}\text { I enjoy discussing about my organization with people outside } \\
\text { it. }\end{array}$ & 0.13 & $\underline{0.71}$ & 0.07 \\
\hline I do feel like 'part of the familiy' at my organization. & 0.11 & $\underline{0.70}$ & 0.05 \\
\hline
\end{tabular}




\begin{tabular}{|c|c|c|}
\hline $\begin{array}{c}\text { Jumping from organization to organization does seem at all } \\
\text { ethical to me. }\end{array}$ & 0.03 & 0.04 \\
\hline $\begin{array}{c}\text { I was taught to believe in the value of remaining loyal to one } \\
\text { organization. }\end{array}$ & 0.01 & 0.12 \\
\hline $\begin{array}{c}\text { I think that people these days move from company to company } \\
\text { too often. }\end{array}$ & 0.04 & 0.18 \\
\hline $\begin{array}{c}\text { I do believe that a person must always be loyal to his or her } \\
\text { organization. }\end{array}$ & 0.12 & 0.09 \\
\hline $\begin{array}{c}\text { Things were better in the days when people stayed in one } \\
\text { organization for most of their careers. }\end{array}$ & 0.19 & 3.42 \\
\hline Eigenvalue & 3.82 & 22.80 \\
\hline \% of variance & 25.47 & 0.59 \\
\hline Cumulative $\%$ & 25.47 & 3.32 \\
\hline Cronbach's alpha & 0.87 & 0.91 \\
\hline
\end{tabular}

\subsection{2. 확인적 요인분석 결과}

본 연구에서 제시한 수출주도형 중소기업의 집단형 리더십에 따른 조직문화가 조직몰입에 미치는 영향에 대한 연구모형을 구조방정식 모형으로 검증하기 전에 확인적 요인분석을 수행하였다. 확인적 요인분석은 측정변수들의 집중타당도와 잠재변수들의 판별타당도를 검증하였다. 집중타당도는 각각의 측정변수가 잠재변수를 얼마나 잘 설명해주는지를 보고, 판별타당도는 잠재변수가 측정하려는 구성개념을 정확하게 측정하고 있는 지를 보았다. 확인적 요인분석을
통해 측정변수가 잠재변수를 얼마나 잘 설명해주는 지를 파악하고자 하였다. 본 연구의 확인적 요인분석 모형 적합도 평가지수는 다음과 같다. $X^{2}=597.299$, 표준적합지수 $(N F)=.984$, 상대적합지수 $(\mathrm{RFI})=.969$, 절대적합지수 $(\mathbb{F F})=.984$, 터커 - 루이스 지수 $(\mathrm{TL})=.968$, 비교적합지수 $(\mathrm{CF})=983$ 으로 나타났다. 따라서 연구모형 적합도는 수용기준을 모두 상회하고 있어서 적합한 것으로 판단하였다.

Table 4: Discrimitive Validity Results for Organizational Culture, Clan Leadership, and Organizational Commitment

\begin{tabular}{|c|c|c|c|c|}
\hline Items & Factor loading & AVE & C.R & SMC \\
\hline The organization is a very controlled and structured place. & 0.88 & \multirow{8}{*}{0.82} & \multirow{8}{*}{12.40} & \multirow{8}{*}{0.53} \\
\hline The glue that holds the organization together is running smooth. & 0.84 & & & \\
\hline $\begin{array}{l}\text { The management style is characterized by security of employment, conformity, predictability, } \\
\text { stability. }\end{array}$ & 0.80 & & & \\
\hline The glue that holds the organization together is formal rules and policies. & 0.77 & & & \\
\hline The organization emphasizes permanence and stability. & 0.87 & & & \\
\hline The organization defines success on the basis of efficiency. & 0.83 & & & \\
\hline The organization emphasizes efficiency and control. & 0.80 & & & \\
\hline $\begin{array}{l}\text { The leadership is generally considered to exemplify coordinating, organizing, or smooth-running } \\
\text { efficiency. }\end{array}$ & 0.78 & & & \\
\hline The organization is a very personal and faclitating. & 0.92 & \multirow{8}{*}{0.79} & \multirow{8}{*}{15.04} & \multirow{8}{*}{0.63} \\
\hline The glue that holds the organization together is loyalty and mutural trust. & 0.84 & & & \\
\hline The management style is characterized by teamwork, consensus, and participation. & 0.83 & & & \\
\hline The glue that holds the organization together is commitment runs high. & 0.76 & & & \\
\hline The organization emphasizes human development. & 0.83 & & & \\
\hline $\begin{array}{l}\text { The organization defines success on the basis of teamwork, employee commitment, and concern for } \\
\text { people. }\end{array}$ & 0.75 & & & \\
\hline The organization emphasizes high trust and participation persist. & 0.73 & & & \\
\hline The leadership is generally considered to exemplify mentoring, or nurturing & 0.66 & & & \\
\hline
\end{tabular}




\begin{tabular}{|c|c|c|}
\hline It would be too costly for me to leave my organization now. & 0.83 \\
\hline Too much in my life would be disrupted if I decided to leave my organization now. & 0.82 \\
\hline It would be very hard for me to leave my organization right now, even if I wanted to. & 0.77 \\
\hline I feel that I have very few options to consider leaving this organization. & 0.76 \\
\hline Right now staying with my organization is matter of necessity as much desire. & 0.75 \\
\hline I really feel as if this organization's problems are my own. & 0.91 \\
\hline I think that I could easily become as attached to another organization as I am to this one. & 0.76 \\
\hline I would be very happy to spend the rest of my career with this organization. & 0.75 \\
\hline I enjoy discussing about my organization with people outside it. & 0.76 \\
\hline I do feel like 'part of the familiy' at my organization. & 0.70 \\
\hline Jumping from organization to organization does seem at all ethical to me. & 0.82 \\
\hline I was taught to believe in the value of remaining loyal to one organization. & 0.81 \\
\hline I think that people these days move from company to company too often. & 0.79 \\
\hline I do believe that a person must always be loyal to his or her organization. & 0.63 \\
\hline Things were better in the days when people stayed in one organization for most of their careers. & 0.59 \\
\hline
\end{tabular}

\section{3. 연구가설 검증 결과}

\subsection{1 조직몰입 전체집단}

조직몰입 전체집단을 대상으로 조직문화가 집단형 리더십과 조직몰입에 미치는 영향을 분석한 결과는 다음과 같다. 먼저, 조직몰입 전체집단의 구조방정식모형에 대한 적합도 평가지수는 다음과 같다. $x^{2}=597299$, 표준적합지수 $(\mathrm{NH})=.984$, 상대적합지수 $(\mathrm{RF})=.969$, 절대적합지수 $(\mathbb{F} \mathrm{H})=.984$, 터커 - 루이스지수 $(\mathbb{L} L)=968$, 비교적합지수 $(\mathrm{CF})=983$ 으로 나타났다. 조직몰입 전체 집단 구조방정식모형의 적합도는 수용기준을 모두 상회하고 있어서 적합한 것으로 판단되었다. 이는 수출주도형 중소기업의 경우, 집단형 리더십이 조직문화와 조직몰입 간의 관계에서 부분매개효과로 작용하였다.

다음으로, 조직문화가 집단형 리더십에 직접적인 영향을 미치며, 이 집단형 리더십에 따라 조직문화가 조직몰입에 간접적인 영향을 미쳤다.
분석결과를 보면, 조직문화 $(\mu=0.447, \mathrm{t}=10.138, \mathrm{p}<.01)$ 가 집단형 리더십 유의한 정(+)의 영향을 미쳤으며, 집단형 리더십 $(\mu=0.353, \mathrm{t}=8.527$, $\mathrm{p}<.01)$ 이 조직몰입에 유의한 정(+)의 영향을 미쳤다. 또한 조직문화 $(\mu$ $=0.317, \mathrm{t}=8.657, \mathrm{p}<.01)$ 가 조직몰입에 유의한 정 $(+)$ 의 영향을 미쳤다. 조직몰입 전체집단을 대상으로 조직문화와 조직몰입 간의 관계에서 집단형 리더십의 매개효과를 검증한 결과, 본 연구에서 제시한 $\mathrm{H} 1, \mathrm{H} 2$, $\mathrm{H} 3$ 의 3 개 연구가설은 모두 채택되었다.

조직몰입 전체 집단에 대한 구조방정식모형을 요약하면, 집단형 리더십이 조직문화와 조직몰입 간의 관계에서 부분매개효과로 작용하였다. 이는 수출주도형 중소기업의 조직문화가 조직몰입에 직접적인 영향을 미치기도 하였으며, 이 조직문화는 집단형 리더십에 직접적인 영향을 미치면서, 동시에 이 집단형 리더십은 조직몰입을 높이는데 긍정적으로 작용하였다.

Table 5: Result for Structured Equation Modeling in Organizational Commitment All Group

\begin{tabular}{|c|c|c|c|c|c|c|c|}
\hline Hypoth-esis & Observation variables & Paths & Observation variables & Estimate & S.E. & C.R. & p \\
\hline H1 & Clan leadership & $\leftarrow$ & Organizational culture & 0.447 & 0.044 & 10.138 & $0.000^{* * *}$ \\
\hline H2 & Organizational commitment & $\leftarrow$ & Clan leadership & 0.353 & 0.041 & 8.527 & $0.000^{* * *}$ \\
\hline H3 & Organizational commitment & $\leftarrow$ & Organizational culture & 0.317 & 0.037 & 8.657 & $0.000^{* * *}$ \\
\hline
\end{tabular}

Note: $* * *: p<0.01, * *: p<0.05, *: p<0.10$.

\subsection{2 조직몰입 고집단}

조직몰입 고집단을 대상으로 조직문화가 집단형 리더십과 조직몰입에 미치는 영향을 분석한 결과는 다음과 같다. 먼저, 조직몰입
고집단의 구조방정식 모형에 대한 적합도 평가지수는 다음과 같다. $x^{2}=327.672$, 표준적합지수 $(\mathrm{NFI})=.971$, 상대적합지수 $(\mathrm{RH})=.927$, 절대적합지수 $(\mathrm{IF})=.970$, 터커 -루이스지수 $(\mathrm{IL})=.928$, 비교적합지수 $(\mathrm{CF})$ 
=. 971 로 나타났다. 조직몰입 고집단 구조방정식 모형의 적합도는 수용기준을 모두 상회하고 있어서 적합한 것으로 판단되었다. 이는 조직몰입이 높은 수출주도형 중소기업의 경우, 집단형 리더십이 조직문화와 조직몰입 간의 관계에서 완전 매개효과로 작용하였다.

다음으로, 조직문화가 집단형 리더십에 직접적인 영향을 미치며, 집단형 리더십은 조직몰입에 긍정적인 영향을 미쳤다. 분석결과를 보면, 조직문화 $(\mu=0.296, \mathrm{t}=4.705, \mathrm{p}<.01)$ 가 집단형 리더십에 유의한 정(+)의 영향을 미쳤으며, 집단형 리더십 $(\mu=0.175, \mathrm{t}=8.657, \mathrm{p}<.01)$ 이 조직몰입에 유의한 정(+)의 영향을 미쳤다. 조직몰입 고집단을 대상으로 조직문화와
조직몰입 간의 관계에서 집단형 리더십의 매개효과를 검증한 결과, 본 연구에서 제시한 $\mathrm{H} 1, \mathrm{H} 2$ 의 2 개 연구가설은 채택된 반면에, $\mathrm{H3}$ 의 연구가설은 기각되었다.

조직몰입 고집단에 대한 구조방정식 모형을 요약하면, 집단형 리더십이 조직문화와 조직몰입 간의 관계에서 완전 매개효과로 작용하였다. 이는 수출주도형 중소기업의 조직문화가 조직몰입에 직접적인 영향을 미치지 않은 반면에, 이 조직문화는 집단형 리더십에 직접적인 영향을 미쳤고, 이 집단형 리더십은 조직몰입을 높이는데 긍정적으로 작용하였다.

Table 6: Result for Structured Equation Modeling in Organizational Commitment High Group

\begin{tabular}{|c|c|c|c|c|c|c|c|}
\hline Hypoth-esis & Observation variables & Paths & Observation variables & Estimate & S.E. & C.R. & p \\
\hline H1 & $\begin{array}{c}\text { Clan } \\
\text { leadership }\end{array}$ & $\leftarrow$ & Organizational culture & 0.296 & 0.063 & 4.705 & $0.000^{* * * *}$ \\
\hline H2 & Organizational commitment & $\leftarrow$ & Clan leadership & 0.175 & 0.053 & 8.657 & $0.000^{* * *}$ \\
\hline H3 & Organizational commitment & $\leftarrow$ & Organizational culture & 0.069 & 0.089 & 1.598 & $0.087^{*}$ \\
\hline
\end{tabular}

Note: $* * *: \mathrm{p}<0.01, * *: \mathrm{p}<0.05, *: \mathrm{p}<0.10$.

\subsection{3. 조직몰입 저집단}

조직몰입 저집단을 대상으로 조직몰입이 $x^{2}$ 집단형 리더십과 조직몰입에 미치는 영향을 분석한 결과는 다음과 같다. 먼저, 조직몰입 저집단의 구조방정식 모형에 대한 적합도 평가지수는 다음과 같다. = 285.129, 표준적합지수 $(\mathrm{NFI})=.961$, 상대적합지수 $(\mathrm{RFI})=939$, 절대적합지수 $(\mathrm{IFI})=.961$, 터커 - 루이스 지수 $(\mathrm{TL})=.938$, 비교적합지수 $(\mathrm{CF})=960$ 으로 나타났다. 조직몰입 저집단 구조방정식 모형의 적합도는 수용기준을 모두 상회하고 있어서 적합한 것으로 판단되었다. 이는 조직몰입이 낮은 수출주도형 중소기업의 경우, 집단형 리더십이 조직문화와 조직몰입 간의 관계에서 매개효과로 작용하지 않았다.

다음으로, 조직문화가 집단형 리더십에 직접적인 영향을 미치며, 집단형 리더십은 조직몰입에 긍정적인 영향을 미치지 않았다. 분석결과를 보면, 조직문화 $(\mu=0.369, \mathrm{t}=4.561, \mathrm{p}<.01)$ 가 집단형 리더십에
유의한 정( +$)$ 의 영향을 미친 반면에, 집단형 리더십 $(\mu=0.080, \mathrm{t}=1620)$ 는 조직몰입에 유의한 영향을 미치지 않았다. 또한 조직문화 $\mu=0.143$, $\mathrm{t}=4.512, \mathrm{p}<.01)$ 가 조직몰입에 유의한 정(+)의 영향을 미쳤으나, 통계적 의미는 없는 것으로 나타났다. 조직몰입 저집단을 대상으로 조직문화와 조직몰입 간의 관계에서 집단형 리더십의 매개효과를 검증한 결과, 본 연구에서 제시한 $\mathrm{H} 1, \mathrm{H} 3$ 의 2 개 연구가설은 채택된 반면에, $\mathrm{H} 2$ 의 연구가설은 기각되었다.

조직몰입 저집단에 대한 구조방정식 모형을 요약하면, 집단형 리더십이 조직문화와 조직몰입 간의 관계에서 매개효과로 작용하지 않았다. 이는 수출주도형 중소기업의 조직문화가 조직몰입에 직접적인 영향을 미친 반면에, 이 집단형 리더십이 조직문화와 조직몰입 간의 관계에서 매개효과로 작용하지 않았다.

Table 7: Result for Structured Equation Modeling in Organizational Commitment Low Group

\begin{tabular}{|c|c|c|c|c|c|c|c|}
\hline Hypoth-esis & Observation variables & Paths & Observation variables & Estimate & S.E. & C.R. & p \\
\hline H1 & Clan leadership & $\leftarrow$ & Organizational culture & 0.369 & 0.081 & 4.561 & $0.000^{* * *}$ \\
\hline H2 & Organizational commitment & $\leftarrow$ & Clan leadership & 0.080 & 0.035 & 1.620 & $0.059^{*}$ \\
\hline H3 & Organizational commitment & $\leftarrow$ & Organizational culture & 0.143 & 0.032 & 4.512 & $0.000^{* * *}$ \\
\hline
\end{tabular}

Note: $* * *: p<0.01, * *: p<0.05, *: p<0.10$.

\subsection{4. 매개효과 검증}

본 연구에서 조직문화와 조직몰입 간의 관계에서 집단형 리더십의 매개효과를 검증하기 위해서 구조방정식 모형(structured equation modeling)을 수행한 후에, 소벨 검증(sobel test)을 통해서 집단형 리더십의 매개효과를 재검증하였다. 분석결과 조직문화 $\mu=0.447, \mathrm{~S} . \mathrm{E}=0.044$, $\mathrm{p}<.01)$ 가 집단형 리더십에 유의한 정(+)의 영향을 미쳤으며, 집단형 
리더십 $(\mu=0.353, \mathrm{~S} . \mathrm{E}=0.041, \mathrm{p}<.01)$ 이 조직몰입에 유의한 정( $(+)$ 의 영향을 미쳤으며, 소벨 검증(sobel test)을 수행한 결과 6568 로 유의수준 $p<.001$ 에서 통계적으로 유의한 것으로 검증되었다. 이는 집단형 리더십이 조직문화와 조직몰입 간의 관계에서 매개효과로 작용하였다는 것을 입증한 결과이다. 본 연구에서 조직문화와 조직몰입 간의 관계에서 집단형 리더십의 매개효과를 체계적으로 검증하기 위해서 조직몰입의 수준에 따라 조직몰입 전체집단, 조직몰입 고집단, 조직몰입 저집단으로 구분하여 분석한 결과, 조직몰입 전체집단은 부분 매개효과로 작용하였고, 조직몰입 고집단은 완전 매개효과로, 조직몰입 저집단은 매개효과가 없는 것으로 분석되었으나, Hayes(2013)의 연구에 기초해서 수출주도형 중소기업의 조직문화와 조직몰입 간의 관계에서 집단형 리더십이 매개효과로 작용하였다고 판단된다.

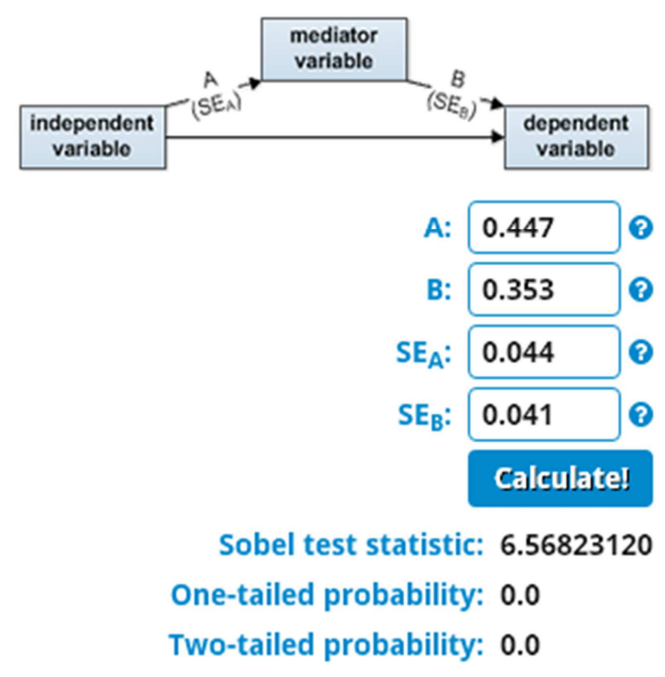

Figure 2: Test of Mediation Effect Using Sobel Test

\section{5. 결론 및 시사점}

본 연구는 수출주도형 중소기업을 대상으로 중소기업의 조직문화와 조직몰입 간의 관계에서 집단형 리더십의 역할을 분석한 결과 다음과 같은 연구결과를 얻었다. 첫째, 조직몰입 전체 집단의 경우에 조직문화와 조직몰입 간의 관계에서 집단형 리더십이 부분 매개효과로 작용하였다. 수출주도형 중소기업의 조직문화가 조직몰입에 직접적인 영향을 미침과 동시에, 집단형 리더십을 통해서 조직문화가 조직몰입에 간접적인 영향을 미쳤다. 조직몰입이 높거나 낮은 기업들을 모두 포함한 전체 수출주도형 중소기업의 조직구성원은 조직 내에 좋은 조직문화를 통해서 자신들이 근무하고 있는 팀과 부서에 대한
조직몰입이 대체적으로 높았다. 이는 집단형 리더십이 잘 발휘되고 있는 수출주도형 중소기업은 다른 기업들에 비해서 조직구성원들의 조직문화가 조직몰입을 강화시키는데 효과적으로 작용하였다.

둘째, 조직몰입 고집단의 경우에 조직문화와 조직몰입 간의 관계에서 집단형 리더십이 완전 매개효과로 작용하였다. 수출주도형 중소기업의 조직문화가 집단형 리더십에 직접적인 영향을 미쳤고, 이 중소기업의 집단형 리더십은 조직몰입을 높이는데 긍정적으로 작용하였다. 이는 수출주도형 중소기업 중에서 조직몰입이 높은 중소기업은 다른 중소기업에 비해서 위계적 조직문화의 유형을 보이고 있으며, 이 위계적 조직문화 안에서 수출주도형 중소기업의 리더는 집단형 리더십을 발휘함으로써 조직몰입을 강화시키는데 효과적으로 작용하였다.

셋째, 조직몰입 저집단의 경우에 조직문화와 조직몰입 간의 관계에서 집단형 리더십이 매개효과로 작용하지 않았다. 수출주도형 중소기업의 조직문화가 집단형 리더십에 직접적인 영향을 미쳤으나, 이 중소기업의 집단형 리더십은 조직몰입을 높이는데 긍정적으로 작용하지 않았다. 이는 조직몰입이 낮은 수출주도형 중소기업은 조직몰입이 높은 중소기업에 비해서 집단형 리더십이 조직문화와 조직몰입 간의 상관관계가 낮았다.

본 연구는 수출기업 중에서 수출주도형 중소기업을 대상으로 중소기업의 조직문화가 조직몰입에 영향을 미치는데 있어서 수출주도형 중소기업의 집단형 리더십이 그 중간에서 어떠한 매개효과로 작용하는가를 분석하였다는 점에서 의미 있는 연구이다. 수출주도형 중소기업 중에서 조직몰입이 높은 기업은 낮은 기업에 비해서 조직문화가 위계적 조직문화가 잘 구축되어 있으며, 이 위계적 조직문화를 통해서 수출주도형 중소기업의 리더가 집단형 리더십을 발휘해서 조직몰입을 강화시킴과 동시에 사업성과를 높이는데 있어서, 이 집단형 리더십이 효과적으로 작용하였다.

본 연구의 수출주도형 중소기업에 대한 시사점은 다음과 같다. 먼저, 정책적 시사점을 보면 산학연계직업훈련체계로 수출주도형 중소기업의 경쟁력을 강화시켜야 한다. 우리나라도 중소기업의 경쟁력을 강화시키기 위해서 다양한 직업훈련 프로그램과 평생학습 프로그램을 운영하고 있으나, 선진국의 직업훈련 및 평생학습 프로그램에 비해서 지속적이고 체계적인 정책적 지원이 미흡하게 운영되고 있다. 유럽국가들 중에서 독일은 세계경제의 침체 속에서도 연평균 $3.0 \%$ 의 경제성장률을 달성하고 있고, 독일의 히든챔피언이 독일의 산업구조와 경제성장의 견인차 역할을 하고 있다. 또한 수출주도형 중소기업을 중심으로 산업 클러스터와 지역혁신체계로 정책적 지원을 집중해야 한다. 국내의 산업 클러스터와 지역혁신체계는 주로 산업정책과 지역경제의 기여도를 기반으로 구축되어 있기 때문에 대기업의 공급망 관리 차원에서 중소기업과 파트너십이 이루어지고 있으나, 선진국은 
히든챔피언 및 강소기업을 중심으로 산업 네트워크가 구축되어서 산업 클러스터와 지역혁신체계를 구축하고 있다는 점에서 차이가 있다.

다음으로, 실무적 시사점을 보면 수출주도형 중소기업의 사회적 책임과 기업가정신을 강화시키기 위해서 경영자원을 집중해야 한다. 수출주도형 중소기업은 조직문화를 혁신하는 차원에서 기업 사회적책임에 집중해야 한다. 우리나라 중소기업은 기업사회적 책임에 대해서 소극적이거나, 선진국에 비해서 사회적 책임에 대한 인식이 낮은 편이다. 오늘날 독일의 히든 챔피언은 대기업보다 더 기업 사회적책임에 적극적으로 경영자원을 집중하고 있다. 또한 수출주도형 기업은 조직 내 중간관리자 이상의 직위에서 선진국 기업들과 경쟁하기 위해서 기업가정신을 통한 리더십을 개발해야 한다. 국내 중소기업은 창업 초기, 혹은 창업 후 3 5년에 기업가정신에 관심을 가지고 있으나, 일본의 강소기업은 창업 초기뿐만 아니라, 중소기업의 발전단계별로 지속적으로 중간관리자의 리더십을 개발하기 위해서 기업가정신에 대한 교육을 활발히 하고 있다.

본 연구는 수출주도형 중소기업의 조직문화와 조직몰입 간의 관계에서 집단형 리더십의 역할을 제한적으로 논의하였는데, 향후의 연구에서는 조직문화와 조직몰입 간의 관계에서 집단형 리더십의 매개효과에 대한 연구모형의 개발, 수출주도형 중소기업에 대한 조사대상표본의 동질성 확보, 조직문화, 조직몰입, 집단형 리더십 변수에 대한 조작적 정의 및 변수측정, 조절변수의 활용 등의 내용이 향후 연구에 반영되어야 하겠다.

\section{References}

Acar, A. Z. (2012). Organizational Culture, Leadership Styles and Organizational Commitment in Turkish Logistics Industry. Procedia Social and Behavioral Sciences, 58, 217-226.

Al-Jabari, B., \& Ghazzawi, I. (2019). Organizational Commitment A Review of the Conceptual and Empirical Literature and a Research Agenda. International Leadership Journal, 11(1), 78-119.

Alkindi, A. M., \& Chaldler, J. (2018). The Impacts of Leadership Styles and Organizational Cultures on Public Innovations in the Emirates. International Journal of Business and Management, 13(7), 1-18.

Alsoulami, S. M., Banjar, H., \& Mahran, S. M. (2018). Assessment of Organizational Culture at Two Governmental Hospitals in Jeddah City. IOSR Journal of Nursing and Health Science, 7(3), 42-51.

Aranki, D. H., Suifan, T. S., \& Sweis, R. J. (2019). The Relationship between Organizational Culture and Organizational Commitment. Modern Applied Science, 13(4), 137-154.

Arditi, D., Nayak, S., \& Damchi, A. (2017). Effect of Organizational Culture on Delay in Construction. International Journal of Project Management, 35(2), 136-147.

Cameron, K. S., \& Quinn, R. E. (2011). Diagnosing and
Changing Organizational Culture: Based on the Competing Values Framework. Jossey-Bass.

Doan, T. T. T., Nguyen, L. C. T., \& Nguyen, T. D. N. (2020). Emotional Intelligence and Project Success: The Roles of Transformational Leadership and Organizational Commitment. Journal of Asian Finance, Economics and Business, 7(3), 223233.

Felipe, C. M., Roldan, J. L., \& Leal-Rodriguez, A. L. (2017). Impact of Organizational Culture Values on Organizational Agility. Sustainability, 9 (2354), 1-23.

Ghassemzadeh, H., Hojabri, R., Eftekhar, F., \& Sharifi, M. (2013). Tacit Knowledge Sharing in Health Industry: Influences of, Personal, Organizational and Social Factors. Journal of Business Economics and Environmental Studies, 3(1), 29-35.

Guiso, L., Sapienza, P., \& Zingales, L. (2015). The Value of Corporate Culture. Journal of Financial Economics, 117, 6076.

Gulosino, C., Franceschini III, L., \& Hardman, P. (2016). The Influence of Bance within the Competing Values Framework and School Academic Success on Teacher Retention. Journal of Organizational Educational Leadership, 2(1), Article 3.

Gungor, S. K., \& Sahin, H. (2018). Organizational Culture Types that Academicians Associate with Thei Institutions. International Journal of Higher Education, 7(6), 161-172.

Hayes, A. F. (2013). Introduction to Mediation, Moderation, and Conditional Process Analysis: A Regression-Based Approach. New York, NY: The Guilford Press.

Igo, T., \& Skitmore, M. (2006). Diagnosing the Organizational Culture of an Australian Engineering Consultancy Using the Competing Values Framework. Construction Innovation, 6(2), $1-31$.

Kang, S. M. (2014). The Effect of Organizational Commitment on Perceived Organizational Justice and Innovative Behavior in Hotel Firms: A Mediating Role of Organizational Commitment. Tourism Research, 39(4), 163-180.

Lee, J. Y. (2018). The Effects of Job Characteristics on the Team Creativity of Distribution Companies: Moderating Effects of Transformational Leadership. Journal of Asian Finance, Economics and Business, 5(4), 161-172.

Lestari, S. D., Muhdaliha, E., \& Putra, A. H. P. K. (2020). ECommerce Performance Based on Knowledge Management and Organizational Innovativeness. Journal of Distribution Science, 18(2), 49-58.

Mastroianni, C. M., Lichtner, M., Mascia, C., Zuccala, P. \& Vullo, V. (2014). Molecular Mechani는 of Liver Fibrosis in HIV/HCV Coinfection. Int J Mol Sci, 15(6), 9184-9208.

McLaren, T. S., Head, M. M., Yuan, Y., \& Chan, Y. E. (2011). A Multilevel Model for Measuring Fit Between A Firm's Competitive Strategies and Information Systems Capability. MIS Quarterly, 35(4), 909-929.

Meiyani, E., \& Putra, A. H. P. K. (2019). The Relationship Between Islamic Leadership on Employee Engagement Distribution in FMCG Industry. Anthropoligy Business Review. Journal of Distribution Science, 17(5). 19-28.

Meyer, J. P., \& Allen, N. N. J. (1997). Commitment in the Workplace: Theory, Research, and Application. Thousand Oaks, CA: Sage Publications.

Mushtaq, A., Amjad, M. S., Bilal, \& Saeed, M. M. (2014). The Moderating Effect of Perceived Alternative Job Opportunities 
between Organizational Justice and Job Satisfaction: Evidence from Developing Countries. Journal of Business Economics and Environmental Studies, 4(1), 5-13.

Nanjundeswaraswamy, T. S., \& Swamy, D. R. (2014). Leadership Styles. Advances in Management, 7(2), 57-62.

Nazarian, A., Atkinson, P., \& Foroudi, P. (2017). Influence of National Culture and Balanced Organizational Culture on the Hotel Industry's Performance. International Journal of Hospitality Management, 63, 22-32.

Razak, M., Gunawan, B. I., Fitriany, A. M., Hidayat, M., \& Aditya, H. P. K. P. (2019). Moving from Traditional to Society 5.0: Case Study by Online Transportation Business. Journal of Distribution Science, 17(9), 93-102.

Shin, H. Y., \& Lee, H. S. (2013). An Analysis of A Structural Causal Relationship among Organizational Justice,
Organizational Commitment, and Innovational Behavior. Korean Public Administration Review, 47(3), 157-179.

Suong, H. T. T., Thanh, D. D., Dao, T. T. X. (2019). The Impact of Leadership Styles on the Engagement of Cardres, Lecturers and Staff at Public University-Evidence from Vietnam. Journal of Asian Finance, Economics and Business, 6(1), 273280.

Szczepanska-Woszczyna, K. (2015). Leadership and Organizational Culture as the Normative Influence of Top Management on Employee's Behaviour in the Innovation Process. Procedia Economics and Finance, 34, 396-402.

Yang, H. C. \& Ju, Y. H. (2011). Positive Integration of the Franchise System: A New Perspective on Leadership, Followship, Trust and Group Efficacy. Journal of Business Economics and Environmental Studies, 1(1), 5-8. 